\title{
Effect of Dynamic Loads on Tall RCC Chimneys of Different Heights with Elliptical and Circular Cross sections
}

\author{
${ }^{1}$ Lokeshwaran.N, ${ }^{2}$ G. Augustine Maniraj Pandian \\ ${ }^{I}$ Assistant Professor, M.Tech Structural Engineering, Department of Civil Engineering, SRM University, \\ Chennai. \\ ${ }^{2}$ Professor, Department of Civil Engineering, SRM University, Chennai.
}

\begin{abstract}
Tall RC chimneys form an important component of major industries and power plants. Since pollution control standards are getting stringent every passing day, the mandatory height requirements of chimneys are increasing. Such increased heights pose structural challenges for designing against dynamic loads such as wind gust and seismic forces. Arriving at an economic and efficient structural profile is one of the important aspects of the analysis and design of tall chimneys. Most of the chimneys constructed in industry are of circular cross section. With increase in heights, chimneys become more vulnerable to dynamic loads. In order to combat these loads and design an economical and efficient structural solution needs to be evolved. Elliptical cross-section provides one such possible alternate solution. Therefore evaluating the behavior of chimneys of varying heights with elliptical cross-section and comparing the same with that of circular cross-section assume significance. Chimneys with circular and elliptical cross sections of five different heights viz. $275 \mathrm{~m}, 300 \mathrm{~m}, 325 \mathrm{~m}, 350 \mathrm{~m}$ and $400 \mathrm{~m}$ with two different profiles in elevation - one tapering from bottom to top and the other tapering from bottom to 2/3 H and straight afterwards - have been analyzed for seismic and vortex shedding effects caused by wind forces; further, analyses have been carried out for three R/t ratios -15, 20 and 25. In total 120 models have been analyzed 60 for seismic forces and 60 for vortex shedding effects. Analytical results in terms of stresses induced on the structure, earthquake base shear, joint acceleration, joint displacements and vortex shedding base shear are evaluated. Maximum values of seismic forces induced base shear is only $1 \%$ of the self weight of the structure for all heights. It is interesting to note that chimneys with elliptical cross section experience less accelerations compared to that with circular cross section. Circular chimneys undergo higher displacement than the elliptical chimneys which is attributed to the higher accelerations they are subjected to by seismic forces. As the height of the chimneys is increased vortex shedding phenomenon induces increased forces compared to that due to earthquakes.
\end{abstract}

Index Terms: Circular and Elliptical chimney, Base shear, Modal frequency, Joint acceleration, Joint displacement, Dynamic loads, Vortex shedding and Seismic forces

\section{Introduction}

Man has always been in search of an effective system to dispose off undesirable gaseous products of combustion which leads to the emergence of chimneys. A chimney is a system for venting hot flue gases or smoke from a boiler or furnace to the outside atmosphere. They are typically almost vertical to ensure that the hot gases flow smoothly, drawing air into the combustion through the chimney effect. Chimneys are tall to increase their draw of air for combustion and to disperse the pollutants in flue gases over a greater area

in order to reduce the pollutant concentrations in compliance with regulatory limits. Chimneys with height exceeding $150 \mathrm{~m}$ are considered as tall chimneys. A modern industrial chimney consists of a concrete windshield with a number of steel stacks on the inside.

Wind is essentially the large scale movement of free air due to thermal currents. It plays an important role in chimney design because of its capacity to transport and disperse pollutants and also because it exerts static and dynamic loads whose effects on a slender structure, such as a chimney, are significant. Tall RCC chimneys undergo severe dynamic loading due to wind gust as well as seismic forces. The aerodynamic profiles of chimneys attract vortex shedding leading to lateral vibrations. MS Excel spread sheets are generated to calculate the wind loads and the vortex shedding at different locations in the chimney.

\section{Objective}

The objective of this project is to evaluate and compare the behaviors of tall RCC chimneys of circular and elliptical cross-sections and of varying heights subjected to dynamic loads including the vortex shedding effects. In order to combat these loads and design an economical and efficient structural solution needs to be evolved. Elliptical cross-section provides one such possible alternate solution. 


\section{Scope}

1. Analysis of tall RCC chimney of height 275 to $400 \mathrm{~m}$.

2. Circular and elliptical cross-sections are considered and 12 models are made in each cross-section by varying the $\frac{R}{t}$ ratio and the profile at various heights.

3. Prismatic and non-prismatic profiles along the height are included in the analysis.

4. Seismic forces as dictated by IS: 1893-2002 response spectrum are imposed on the structure and dynamic effect of wind including that of vortex shedding is studied.

5. Key output parameters like base shear, joint acceleration and joint displacements are studied.

6. Efficient and economic alternative between chimneys of circular and elliptical cross-sections is arrived at.

\section{Modelling}

The chimneys designed in this project are of five different heights. They are $275 \mathrm{~m}, 300 \mathrm{~m}, 325 \mathrm{~m}, 350 \mathrm{~m}$ and $400 \mathrm{~m}$. The heights are considered according to data acquired from Neyveli Lignite Corporation (NLC). The normal height adopted for chimney in India is $275 \mathrm{~m}$. But thinking of stringent environmental constraints in future this height may not be sufficient for disposing the gaseous products as it will pose a serious threat causing air pollution. So increasing the height of the chimney would be a better idea to meet out the environmental challenges.

Considering chimney as a thin shell structure, varying the $\frac{R}{t}$ ratio for three different values such as 15,20 and 25 the chimneys are modeled. The cross-section of the chimney used is circular and elliptical. Two variations are shown in the profile of both the cross-sections such as

1. Tapering from the bottom and becomes uniform at a height of one-third from the top of the structure considering it as a critical section.

2. Uniformly tapering from bottom to the top of the structure.

According to NLC the shell thickness also varies from bottom to the top of the structure. The minimum shell thickness at the top of the structure is taken as 0.35 to $0.4 \mathrm{~m}$. The bottom shell thickness can be taken as per code design requirements. Totally in this project 60 models are created for both circular and elliptical chimneys of 30 each. For $\frac{R}{t}=15,20$ and 25 totally 60 models are created for all the five different heights and two different profile variations of 20 models each. The details of the models are summarized in Table 1.

\section{Seismic analysis and design}

The analysis for the earthquake forces are done by response spectrum method. It includes arriving of thickness and the diameter of the chimney by optimizing the stresses to be within that specified for M35 grade concrete for seismic forces. The stresses in the compression for both earthquake and the self weight of chimney are in the range of 3.4 to $4.03 \mathrm{~N} / \mathrm{mm}^{2}$ for $275 \mathrm{~m}, 3.79$ to $3.91 \mathrm{~N} / \mathrm{mm}^{2}$ for $300 \mathrm{~m}, 3.42$ to $4.38 \mathrm{~N} / \mathrm{mm}^{2}$ for $325 \mathrm{~m}, 3.8$ to $3.95 \mathrm{~N} / \mathrm{mm}^{2}$ for $350 \mathrm{~m}$ and 3.7 to $4.94 \mathrm{~N} / \mathrm{mm}^{2}$ for $400 \mathrm{~m}$ height chimneys of both circular and elliptical sections. The stress optimization graph is plotted for all the five heights and shown in Figure 1.

Table 1 Structural models of chimney

\begin{tabular}{|c|c|c|c|c|c|c|c|c|}
\hline \multirow{2}{*}{$\begin{array}{c}\text { Height } \\
\text { (m) }\end{array}$} & \multicolumn{4}{|c|}{ Circular cross section } & \multicolumn{4}{|c|}{$\begin{aligned} \text { Elliptical cross section } \\
\end{aligned}$} \\
\hline & $\begin{array}{l}\text { Model } \\
\text { name }\end{array}$ & $\frac{K}{t}=15$ & $\frac{K}{t}=20$ & $\frac{K}{t}=25$ & Model name & $\frac{K}{t}=15$ & $\frac{K}{t}=20$ & $\frac{K}{t}=25$ \\
\hline \multirow[t]{2}{*}{275} & M1C & UT & UT & UT & M1E1 / M1E2 & UT & UT & UT \\
\hline & $\mathrm{M} 2 \mathrm{C}$ & TS & $\mathrm{TS}$ & $\mathrm{TS}$ & M2E1 / M2E2 & TS & $\mathrm{TS}$ & TS \\
\hline \multirow[t]{2}{*}{300} & M1C & UT & UT & UT & M1E1 / M1E2 & UT & UT & UT \\
\hline & $\mathrm{M} 2 \mathrm{C}$ & TS & TS & TS & M2E1 / M2E2 & TS & TS & TS \\
\hline \multirow[t]{2}{*}{325} & $\mathrm{M} 1 \mathrm{C}$ & UT & UT & UT & M1E1 / M1E2 & UT & UT & UT \\
\hline & $\mathrm{M} 2 \mathrm{C}$ & TS & TS & TS & M2E1 / M2E2 & TS & TS & TS \\
\hline \multirow[t]{2}{*}{350} & M1C & UT & UT & UT & M1E1 / M1E2 & UT & UT & UT \\
\hline & $\mathrm{M} 2 \mathrm{C}$ & TS & TS & TS & M2E1 / M2E2 & TS & TS & TS \\
\hline \multirow[t]{2}{*}{400} & $\mathrm{M} 1 \mathrm{C}$ & UT & UT & UT & M1E1 / M1E2 & UT & UT & UT \\
\hline & $\mathrm{M} 2 \mathrm{C}$ & TS & TS & TS & M2E1 / M2E2 & TS & TS & TS \\
\hline \multicolumn{9}{|c|}{$\begin{array}{l}\text { UT - Uniformly tapering cross section from bottom to top } \\
\text { TS - Tapering in cross section from bottom to } \frac{z}{z} H \text { and from } \frac{z}{z} H \text { to top }(\mathrm{H}) \text { uniform } \\
\text { chimney } \\
\text { M1 and M2 denotes UT and TS respectively } \\
\text { E1 and E2 indicates minor and major axes for elliptical cross section }\end{array}$} \\
\hline
\end{tabular}




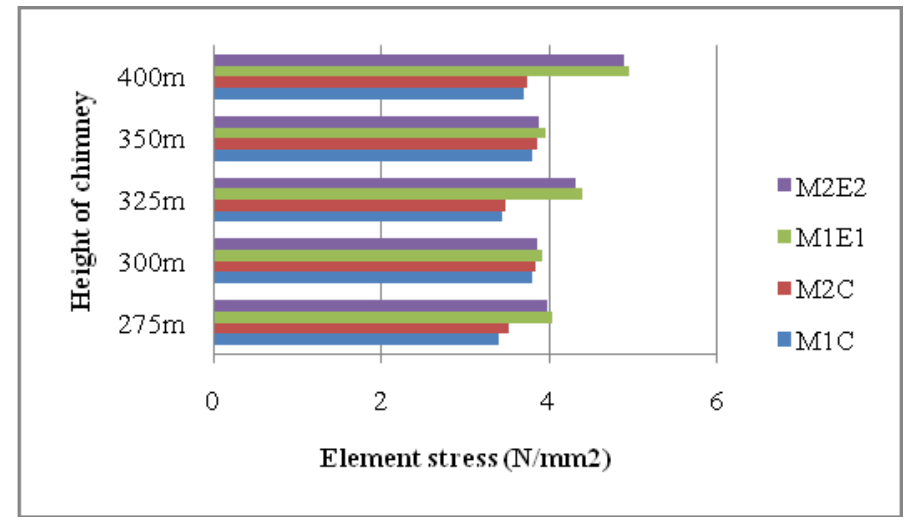

Fig. 1 Stress optimization graph

\section{Analysis for vortex shedding}

This phenomenon creates cross-wind dynamic forces which can lead to transverse vibrations. The frequency at which the vortex shedding takes place is determined by Strouhal number and it is shown below.

$$
\bar{U}_{c}=\frac{n_{i} \cdot L_{c o}}{S t}
$$

where $S t$ is Strouhal number, $\bar{U}_{c}$ is the critical wind velocity which can generate vortex shedding, $n_{i}$ is the fundamental frequency of the structure and $D_{c o}$ is the diameter of the structure at one third height from top.

Using Strouhal number here and introducing an equation,

$$
q_{i}=\frac{\rho_{a}}{16 \cdot \pi^{2} \cdot(S t)^{2}} \cdot \frac{0.6 \sqrt{\bar{C}_{L}^{2}}}{\beta} \cdot D_{c 0}^{2} \cdot \frac{\int_{0}^{H} D_{z} \cdot \varphi_{z i} \cdot d z}{\int_{0}^{H} m \cdot \varphi_{z i}^{2} \cdot d z}
$$

where $\rho_{a}=$ air density, $\beta=$ damping factor 0.05 and $\varphi_{z i}=$ mode shape value.

The transverse modal force due to the vortex-induced excitation at each mass level can be obtained by the formula Vortex-induced excitation force $=M_{r}, \varphi_{r} \cdot \omega_{1}^{2} \cdot q_{i}$

\section{Results and discussion}

The base shear is computed and expressed as a percentage of the self weight of the structure, called base shear index BSI so that this value can be compared across the models of different heights.

Base shear index $=$ BSI $=\frac{\text { Base shear }}{\text { Self weight of the structure }} \times 100$

The EQBSI AND VSBSI for all the five heights are plotted and its characteristics are discussed below.

EQBSI for various heights is shown in the Figure 2.

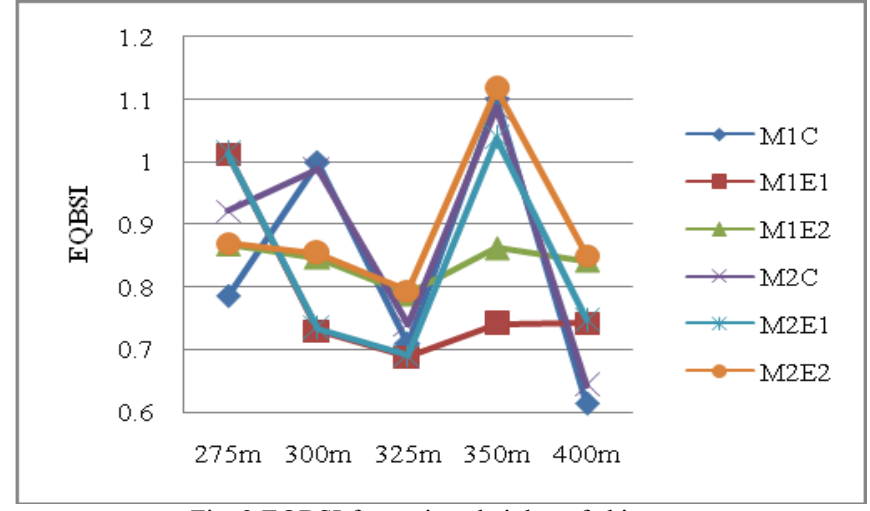

Fig. 2 EQBSI for various heights of chimney

From this graph it is evident that up to a height of $325 \mathrm{~m}$ starting from $275 \mathrm{~m}$, there is a decline in earthquake induced base shear which goes up for the height 350 and then falls to the lowest value when the height is $400 \mathrm{~m}$. Chimneys with heights ranging from $325 \mathrm{~m}$ to $350 \mathrm{~m}$ are vulnerable against seismic forces especially those with elliptical cross section. 
VSBSI for various heights is shown in the Figure 3.

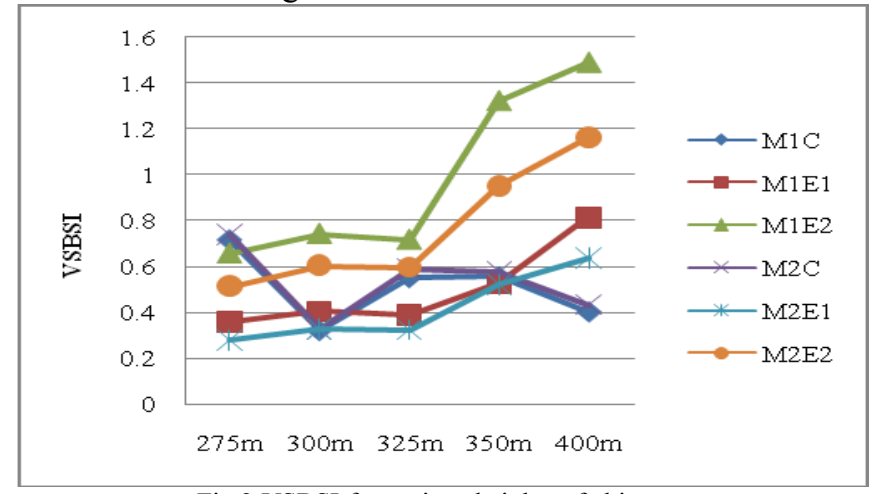

Fig.3 VSBSI for various heights of chimney

From this graph it is clear that beyond $325 \mathrm{~m}$ height chimneys are susceptible to vortex shedding phenomenon. Chimneys with circular cross section undergo less base shear.

\section{Joint Acceleration}

Joint accelerations vary from $2.54 \times 10^{-2} \mathrm{~m} / \mathrm{s}^{2}$ to a maximum value of $9.58 \times 10^{-2} \mathrm{~m} / \mathrm{s}^{2}$, the maximum experienced by the $275 \mathrm{~m}$ tall chimney with $\mathrm{R} / \mathrm{t}$ ratio equal to 15 . It is interesting to note that chimneys with elliptical cross section experience less accelerations compared to that with circular cross section. The joint acceleration graph for ratio $\mathrm{R} / \mathrm{t}=15$ is plotted as graph shown in Figure 4.

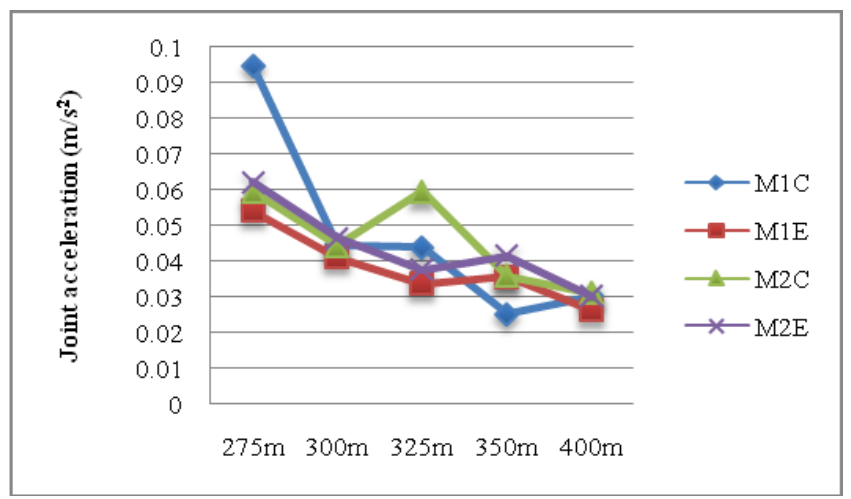

Fig.4 Joint acceleration graph

\section{Joint Displacement}

All the maximum joint displacements due to seismic forces are less than the codal stipulated value of $0.004 \mathrm{H}$. However circular chimneys undergo higher displacement than the elliptical chimneys which is attributed to the higher accelerations they are subjected to by seismic forces. The joint displacement graph for ratio $\mathrm{R} / \mathrm{t}=15 \mathrm{is}$ plotted as graph shown in Figure 5.

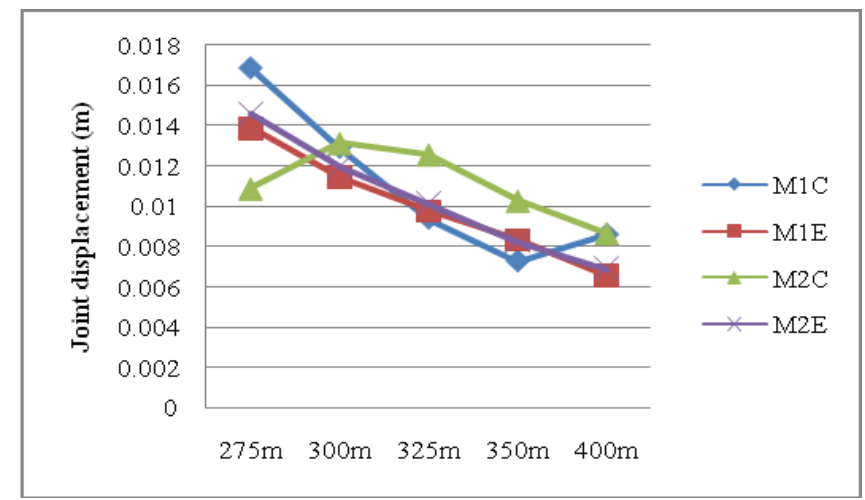

Fig. 5 Joint displacement graph 


\section{Conclusion}

Chimneys with circular and elliptical cross sections of five different heights viz. $275 \mathrm{~m}, 300 \mathrm{~m}, 325 \mathrm{~m}$, $350 \mathrm{~m}$ and $400 \mathrm{~m}$ with two different profiles in elevation - one tapering from bottom to top and the other tapering from bottom to $2 / 3 \mathrm{H}$ and straight afterwards - have been analyzed for seismic and vortex shedding effects caused by wind forces; further, analyses have been carried out for three R/t ratios - 15, 20 and 25 . In total 120 models have been analyzed 60 for seismic forces and 60 for vortex shedding effects. Analytical results in terms of stresses induced on the structure, earthquake base shear, joint acceleration, joint displacements and vortex shedding base shear are evaluated. The results indicate that output parameters for circular and elliptical cross-sections show significant variations.

The main conclusions are enumerated below:

- Considering the base shear caused by seismic forces it is found that increase in the $\frac{R}{t}$ ratio will lead to decrease in the base shear values. Because of slenderness of chimneys of heights $275 \mathrm{~m}$ and above the maximum induced base shear due to seismic forces is just around $1 \%$ of the weight of the structure. The higher values are experienced by the chimneys with elliptical cross section. Chimneys with heights ranging from $325 \mathrm{~m}$ to $350 \mathrm{~m}$ are vulnerable against seismic forces especially those with elliptical cross section.

- As the heights of the chimneys are increased, vortex shedding phenomenon induces increased forces compared to that due to earthquakes.

- Joint accelerations vary from $2.54 \times 10^{-2} \mathrm{~m} / \mathrm{s}^{2}$ to a maximum value of $9.58 \times 10^{-2} \mathrm{~m} / \mathrm{s}^{2}$, the maximum experienced by the $275 \mathrm{~m}$ tall chimney with $\mathrm{R} / \mathrm{t}$ ratio equal to 15 . It is interesting to note that chimneys with elliptical cross section experience less accelerations compared to that with circular cross section.

- All the maximum joint displacements due to seismic forces are less than the codal stipulated value of $0.004 \mathrm{H}$. However circular chimneys undergo higher displacement than the elliptical chimneys which is attributed to the higher accelerations they are subjected to by seismic forces.

- The evaluation of base shear induced by vortex shedding effects caused by dynamic wind reveals that in models with uniform taper, circular cross sections suffer reduced base shear for $\mathrm{R} / \mathrm{t}$ values 20 and 25 . For $\mathrm{R} / \mathrm{t}=15$, it is higher than that of chimneys with elliptical cross section. However elliptical chimneys with taper and straight portions undergo less base shear compared with chimneys with circular cross section. Beyond $325 \mathrm{~m}$ height chimneys are susceptible to vortex shedding phenomenon.

\section{References}

[1]. S. Chen, B. Mulgrew, and P. M. Grant, "A clustering technique for digital communications channel equalization using radial basis function networks," IEEE Trans. on Neural Networks, vol. 4, pp. 570-578, July 1993.

[2]. Alok David John, Ajay Gairola, Eshan Ganju and Anant Gupta , "Design Wind Loads On Reinforced Concrete Chimney- An Experimental Case Study," The Twelfth East Asia-Pacific Conference on Structural Engineering and Construction Procedia Engineering, 2011

[3]. IS 1893(Part1) - 2002, "Indian Standard Code of Practice for Criteria for Earthquake Resistant Design of Structures", BIS (New Delhi).

[4]. IS 2210 - 1988, "Indian Standard Code of Practice for Criteria for Design of Reinforced Concrete Shell structures and folded plates", BIS (New Delhi).

[5]. John L Wilson, "Performance of Tall Reinforced Concrete Chimney Structures in the 2010 Chilean Earthquake", Australian Earthquake Engineering Society 2010 Conference, Perth, Western Australia, 2011

[6]. John L Wilson, "Code Recommendations for the Aseismic Design Of Tall Reinforced Concrete Chimneys", CICIND 53rd Meeting, University of Melbourne, Australia, Bilbao, Volume 16, No 2, 2000

[7]. Mendis P, Ngo T, Haritos N, Hira A, Samali B and Cheung J, "Wind Loading on Tall Buildings", EJSE Special Issue: Loading on Structures, 2011

[8]. Lakshmanan N, Arunachalam S, Selvi Rajan S, Ramesh Babu G and Shanmugasundaram J, 'Correlations of Aerodynamic Pressures for Prediction of Across Wind Response of Structures', Structural Engineering Research Centre, Wind Engineering Laboratory, Madras, India, 2002

[9]. Reddy K.R.C, Jaiswal O.R and Godwale P.N, "Wind and Earthquake Analysis of Tall RC Chimneys", International Journal of Earth Sciences and Engineering ISSN 0974-5904, Volume 04, No 06 SPL, pp. 508-511, 2011

[10]. Shaikh MIE and M.G Khan H.A.M.I, "Governing Loads For Design of a Tall RCC Chimney", Journal of Mechanical and Civil Engineering (IOSR-JMCE), ISSN: 2278-1684, pp. 12-19

[11]. Siva Konda Reddy B, Rohini Padmavathi V and Srikanth Ch, "Study of Wind Load Effects on Tall RC Chimneys", IJAET/Vol.III/ Issue II, 2012

[12]. Sule S and Nwofort C, "Wind Induced Vibration of a Tall Steel Chimney", Canadian Journal on Environmental, Construction and Civil Engineering, Civil/Environmental Engineering, University of Port Harcourt. Vol. 3, No 2, 2012

[13]. S. N. Manohar, "Tall Chimneys - Design and Construction", 1985, TAT A McGraw - Hill Publishing Company Limited. 